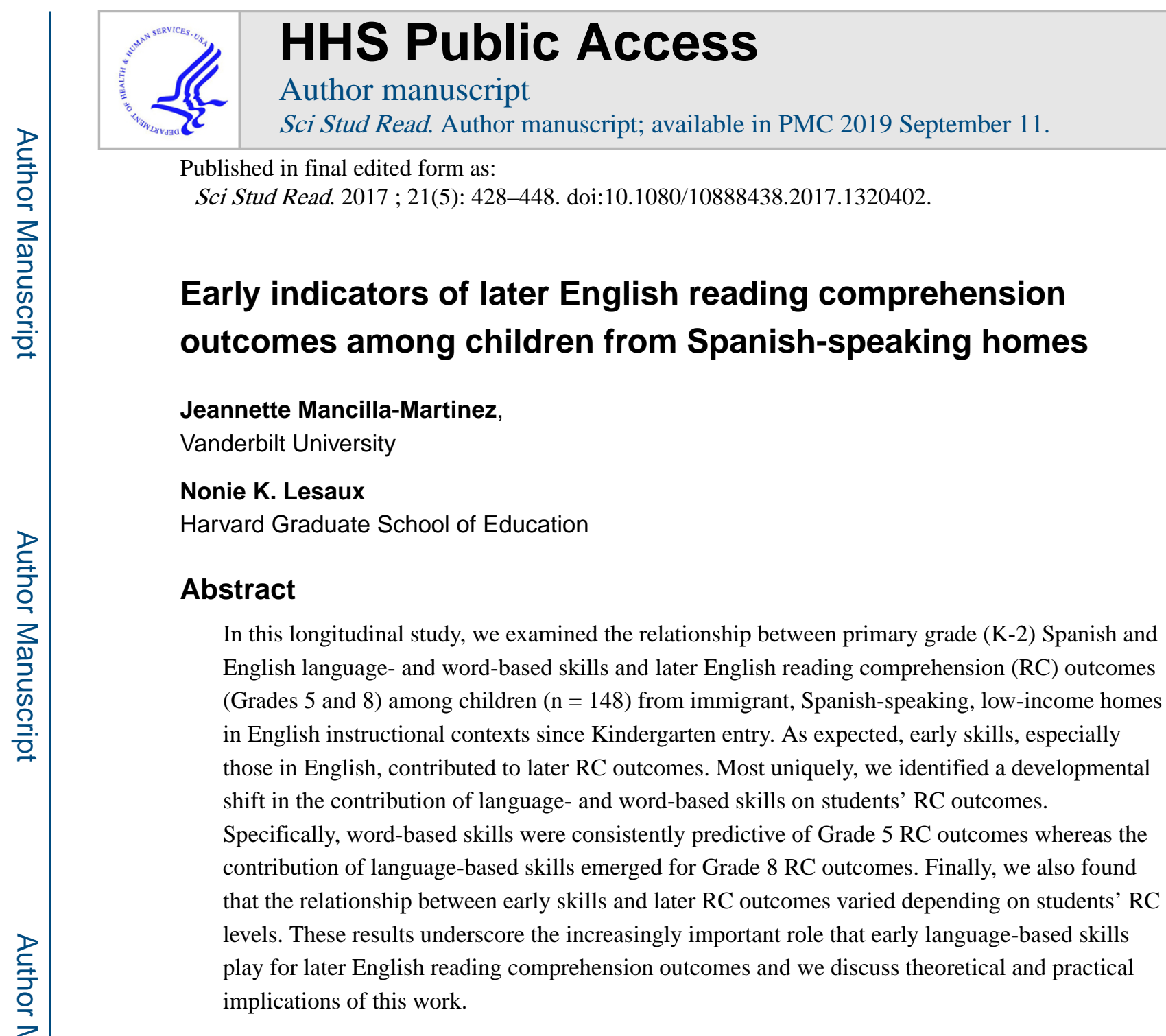

Many students whose first language is not English, referred to here as Language Minority (LM) learners, struggle to comprehend English text more so than their native-English speaking peers. These reading achievement gaps persist even when examining the literacy levels of the large and growing population of LM learners born, raised, and educated in the U.S. (Murphey, Guzman, \& Torres, 2014). If we are to effectively work toward closing the achievement gaps, effective early identification of LM learners who may go on to experience later reading comprehension difficulties is imperative. While efforts to better understand factors that relate to LM learners' reading outcomes have increased over the years, extant reading development research has generally focused on the word reading rather than the reading comprehension domain. Furthermore, few longitudinal studies have tracked Spanish-speaking LM learners' early language and literacy skills (Hammer, Hoff, Uchikoshi, Gillanders, Castro, \& Sandilos, 2014) and their relationship to later reading comprehension outcomes. Given that the language demands of text increase across the school years (Stevens, Lu, Baker, Ray, Eckert, \& Gamson, 2015)—thus drawing on students' language comprehension skills (Perfetti, 2007)—, we need empirical investigations

Correspondence concerning this article should be addressed to Jeannette Mancilla-Martinez, Vanderbilt University, Peabody College, 230 Appleton Place, Nashville, TN 37203-5721. Office: 615.875.9452. jeannette.mancilla-martinez@ vanderbilt.edu. 
of whether early language and literacy skills exert similar or differential impacts on reading comprehension outcomes over time, through the elementary and middle school years.

An additional consideration is that the relation of early language and literacy skills on reading outcomes may depend upon the grade level(s) in which skills are assessed and/or on students' individual reading comprehension levels. It is thus important to examine the nature of this relationship at discrete points in time and across the primary grade years, as well as across the distribution of reading comprehension performance. Furthermore, we need an understanding of the relation of students' Spanish skills on English reading comprehension outcomes at distinct points in development.

To address these issues, we draw on data from a longitudinal study of 148 U.S.-born, English-instructed Spanish-speaking LM learners who are children of immigrants from lowincome homes. Specifically, we examine the relation of their language and literacy skills on later reading comprehension outcomes and do so by examining the relation of Spanish and English skills at discrete points in time (i.e., Kindergarten, Grade 1, and Grade 2) and on average across time (i.e., Kindergarten through Grade 2), on English reading comprehension at $5^{\text {th }}$ and $8^{\text {th }}$ grade. Results of this study are intended to inform models of early identification for later reading comprehension difficulties among children from Spanishspeaking, low-income homes provided with English-only instruction since formal school entry.

\section{Predictors of Reading Comprehension among Monolingual Learners}

The Simple View of Reading (SVR) (Gough \& Tunmer, 1986) is one of the most influential and parsimonious models of reading comprehension. There is wide consensus that, as posited by the SVR, language comprehension and word reading are fundamental building blocks for skilled reading. Numerous studies conducted with native English speakers (e.g., Catts, Adlof, \& Weismer, 2006; Catts, Nielsen, Bridges, \& Liu, 2014; Johnston \& Kirby, 2006; Olson, Keenan, Byrne, Samuelsson, Coventry, Corley, Wadsworth, Willcut, DeFries, Pennington, \& Hulslander, 2011; Vellutino, Tunmer, Jaccard \& Chen, 2007) provide empirical support for the important roles that language comprehension and word reading play in students' reading comprehension skills.

Notwithstanding the empirical support for the SVR model, few studies have examined whether early language comprehension and word reading skills predict later reading comprehension outcomes. Instead, the focus has generally been on word reading outcomes in the primary grade years (Catts, Fey, Zhang, \& Tomblin, 2001; Schatschneider, Fletcher, Francis, Carlson, \& Foorman, 2004). Olson and colleagues' (2011), as well as Catts and colleagues' (2014) work represent notable exceptions to this trend. Utilizing the International Longitudinal Twin Study (ILTS), Olson and colleagues explored the genetic and environmental relation of vocabulary, word recognition, decoding, and reading comprehension among identical and fraternal twins (all monolingual speakers). They examined the relationship between preschool vocabulary, word recognition, and decoding skills on students' Grade 2 and 4 reading comprehension outcomes, finding strong longitudinal genetic and environmental correlations between preschool vocabulary and 
Grade 4 reading comprehension. In a similar study conducted in a U.S., monolingual English-speaking context, Catts and colleagues investigated the relation of kindergarten language comprehension and word reading skills on Grade 3 reading comprehension outcomes; indeed, they are the first to directly study the SVR model for predicting reading comprehension outcomes. Findings revealed that the language measures predicted reading comprehension outcomes above and beyond the word reading measures. Thus, the authors assert that use of both language comprehension and word reading measures can be used to screen children who might go on to experience reading comprehension difficulties. Like Olson and colleagues, Catts and colleagues specifically underscore the important role of vocabulary as a unique predictor of later reading comprehension outcomes among the monolingual speakers they studied.

Furthermore, Johnston and Kirby (2006) examined the contribution of naming speed to the SVR among upper elementary monolingual Canadian English speakers, finding a small but significant effect. Of relevance is that they also divided the sample at the median of Grade 3 word reading scores to identify poor and good readers and examine the influence of naming speed by subgroup. The subgroup regression analysis revealed that naming speed had more of an effect on the poor readers. Results of the subgroup analysis suggest that the influence of reading comprehension predictors may hinge on students' reading levels.

\section{Predictors of Reading Comprehension among LM Learners}

Research conducted with Spanish-speaking LM learners in the U.S. from low-income homes (e.g., Hoover \& Gough, 1990; Mancilla-Martinez \& Lesaux, 2010; Nakamoto, Lindsey, \& Manis, 2008; Proctor, Carlo, August, \& Snow, 2005) confirms the role that language comprehension and word reading skills play in students' reading comprehension outcomes. However, to our knowledge, there are no longitudinal studies that examine whether early language comprehension and word reading skills predict later English reading comprehension outcomes among this population. What we do know is that LM learners instructed in English-only contexts since school entry typically develop English word reading, but not English language comprehension, skills on par with their monolingual English peers (Mancilla-Martinez \& Lesaux, 2011). As such, the typical profile for Spanishspeaking LM learners appears to be one in which, under typical instructional conditions, the development of English word reading skills is not as salient a concern as their development of English language comprehension and reading comprehension.

\section{Building a Model of Early Identification for LM Learners}

There is wide consensus about the importance of preventing children's reading comprehension difficulties (e.g., Snow, Burns, \& Griffin, 1998). Yet, we have a limited knowledge base regarding early indicators of later reading comprehension difficulty; as noted, extant research has largely focused on predicting learners' word reading outcomes. This is especially the case for Spanish-speaking LM learners. Despite their widespread reading challenges, generating an early "at-risk" identification for later reading comprehension difficulties among this population of learners is a complex undertaking. Given that reading is a language-based skill, an "at-risk" identification for LM learners 
during the primary grades may be premature, reflecting their soon-to-be-developed English language skills. However, early identification can enable schools to target early intervention efforts towards children most likely to encounter reading comprehension difficulties. Getting to an effective model for this population thus demands addressing four key elements: the early skills that are the strongest predictors; the point in time in which early skills should be assessed; the appropriate language(s) in which to identify the risk; and the analytic approach that best represents the nature of the relationship between early skills and later outcomes.

On the skills themselves, research with monolingual English (Catts et al., 2014) and Spanish-speaking LM learners (Mancilla-Martinez \& Lesaux, 2010; 2011) suggests that the assessment of language comprehension and word reading beginning in the primary grade years may represent an important way to identify children who go on to develop reading comprehension difficulties. While the prediction of language comprehension and word reading on reading comprehension outcomes is expected to shift over the course of development (e.g., Catts, Hogan, \& Adlof, 2005; Vellutino et al., 2007), for Spanishspeaking LM students, and in contrast to the general population, word reading often continues to be the strongest predictor of reading comprehension at the end of the elementary school years. It seems that developmental shifts in the contributions of language comprehension and word reading skills to reading comprehension presumes that the reader has age-appropriate comprehension skills. An unanswered question is whether the prediction of early language and literacy skills during the primary grade years shifts over the course of reading comprehension development.

Concerning the point in time in which skills are assessed, the goal is to identify risk for reading comprehension difficulties as early as possible (Snow, Burns, \& Griffin, 1998) rather than to remediate such difficulties in later grades (Torgesen, 2002). This recommendation applies to LM learners (McCardle, Mele-McCarthy, Cutting, Leos, \& D’Emilio, 2005). However, that reading is a language-based skill makes "at-risk" identification for LM learners a challenging undertaking. At the same time, if instructional supports to mitigate reading comprehension difficulties among LM learners are to be provided, it is imperative to examine the relationship between early language comprehension and word reading skills (as early as the primary grade years) on later reading comprehension outcomes.

Additionally, because LM learners, by definition, come from non-native English speaking homes, native language skills must be considered in evaluating LM learners who may be at risk for reading comprehension difficulties. This is a complex issue; with few exceptions (e.g., Proctor, August, Carlo, \& Snow, 2006), work that has attended to Spanish and English skills in predicting Spanish-speaking LM learners' English reading comprehension outcomes tends to find that Spanish skills do not typically contribute unique variance above and beyond the prediction of English skills (Lindsey, Manis, \& Bailey, 2003; Manis, Lindsey, \& Bailey, 2004; Mancilla-Martinez \& Lesaux, 2010). An important point to underscore here is that the majority of Spanish-speaking LM learners in the U.S. attend English-only instructional schools, placing a limit on what we can expect regarding the contribution of Spanish skills to English reading comprehension. Indeed, when it comes to LM learners' word-based skills, use of English-only measures, independent of language of instruction, may be justifiable given cross-linguistic research that demonstrate positive 
transfer from the native language to the second language (Cárdenas-Hagan, Carlson, \& Pollard-Durodola, 2007; Durgunoglu et al., 1993; Melby-Lervåg \& Lervåg, 2011). In contrast, language comprehension skills either evidence a negative or insignificant correlation across languages (Cárdenas-Hagan, Carlson, \& Pollard-Durodola, 2007; Mancilla-Martinez \& Lesaux, 2010; Mancilla-Martinez \& Vagh, 2013; Melby-Lervåg \& Lervåg, 2011) suggesting that, even if instruction is provided only in English, a comprehensive model of English reading comprehension for LM learners must attend to native language skills.

Finally, studies to date have focused on predicting LM learners' reading comprehension outcomes using classical regression approaches, providing a generally good handle on reading comprehension outcomes for students whose performance falls roughly at the mean of the reading comprehension distribution. But a classical regression approach provides limited insight into the performance of students whose comprehension falls at the lower or higher ends of the mean. As a result, use of classical regression approaches may not represent the best mechanism by which to elucidate the relationship between early predictors and later reading comprehension outcomes for some LM learners. We thus need to supplement classical regression with quantile regression to examine the prediction of foundational language and literacy skills on later reading comprehension outcomes across the distribution of reading comprehension outcomes (Koenker \& Bassett, 1978). By doing so, we may obtain a more nuanced understanding of the extent to which the relationship holds depending on students' reading comprehension levels.

\section{Present Study}

Utilizing the SVR theoretical framework (Gough \& Tunmer, 1986), this longitudinal study investigates the relationship between primary grade Spanish and English language- and word-based skills to English reading comprehension outcomes at two important points in development - the end of the elementary and middle school years-for a sample of children from immigrant, Spanish-speaking, low-income homes in English-only instructional contexts since Kindergarten entry $(n=148)$. Results of this longitudinal study have the potential to inform models of early identification of later reading comprehension difficulties for the large and growing population of LM learners from Spanish-speaking, low-income homes in the U.S. Two main research questions guide the study:

1. What is the relative single-year prediction of Spanish and English language- and word-based skills in Kindergarten, Grade 1, and Grade 2 on English reading comprehension outcomes in Grades 5 and 8?

2. What is the relative prediction of average performance on Spanish and English language- and word-based skills across Kindergarten, Grade 1, and Grade 2 on English reading comprehension outcomes in Grades 5 and 8 ? 


\section{Method}

\section{Participants}

This study utilized longitudinal data collected in two phases. In Phase 1, data were gathered as part of the five-year Acquiring Literacy in English component of the Development of Literacy in Spanish Speakers project, funded by the National Institute of Child Health and Human Development and the Institute of Education Sciences. During the 2001-2002 academic year, 387 families were recruited for participation from 14 Head Start programs and 2 public preschool programs in a Northeastern U.S city. All selected families reported Spanish as the primary language of the home. Participating children were followed each year from Preschool through Grade 2, with 243 children (63\%) participating through Grade 2. In Phase 2, when children were in Grade 5 (2007-2008 academic year), contact information was not available for 67 of the 243 families (28\%) owing to telephone numbers that had changed or were no longer in service. Of the 176 families for whom current contact information was available in Grade 5, only 3 families refused to participate, yielding a sample size of 173. In Phase 2, children were followed through the end of Grade 8, with $86 \%$ successfully followed from Grade 5 to Grade 8 . The final sample size for this study is 148, with students attending 73 different middle schools. T-tests results revealed no significant differences in family income, home language use prior to formal school entry, or Spanish and English word- and language-based skills between children who were and were not successfully recruited for participation during Phase 2 (Author, 2011). Nearly all students (95\%) were educated in English-only classrooms since Kindergarten.

Phase 1 demographic and language use data was collected from a parent phone interview administered in Spanish and English, depending on parent preferences. The great majority of children (90\%) were born in the U.S., and nearly all parents (97\%) identified their children as Latino. In contrast, the great majority of mothers (89\%) and fathers (90\%) were born outside of the U.S. mainland, primarily in the Dominican Republic, Puerto Rico, and El Salvador. On average, mothers and fathers had less than a high school education (11.7 years and 10.8 years, respectively). We asked parents to report their annual household income, the total number of people living in the home, and the total number of people under age 18 living in the home. To account for differences in total family size, as well as for inflation, we computed the income-to-needs ratio by dividing total family income by the poverty threshold for the appropriate family size (U.S. Census Bureau, 2001). Ninety percent of families were low-income, with 52\% living in poverty. At study entry, $78 \%$ of parents or guardians reported using only or mostly Spanish at home with children, $14 \%$ reported using approximately equal amounts of both languages, and 8\% reported using mostly English at home. Further, reflecting the recruitment criteria, none of the children received all of their linguistic input exclusively in English.

\section{Procedure}

Children were tested by college-educated Spanish-English bilingual research assistants trained to administer the individual assessments each year in a quiet room at the children's schools, homes, in community libraries, or after-school programs. 


\section{Measures}

\section{Language-Based Skills}

Vocabulary.-Spanish and English productive vocabulary skills were assessed with the Expressive Vocabulary subtest from the Woodcock Language Proficiency Battery-Revised (WLPB-R; Woodcock, 1991; Woodcock \& Muñoz-Sandoval, 1995) in Kindergarten, Grade 1 , and Grade 2. Children named pictured objects that were ordered by increasing difficulty. Median internal consistency reliability is .91 for Spanish and .86 for English.

Verbal Short-Term Language Memory.-Spanish and English verbal short-term language memory skills were assessed with the Memory for Sentences subtest from the WLPB-R (Woodcock, 1991; Woodcock \& Muñoz-Sandoval, 1995) in Kindergarten, Grade 1 , and Grade 2. Children heard and then repeated a word/phrase/sentence(s). Median internal consistency reliability is .88 for Spanish and .90 for English. We utilized this measure as it taps into both semantic and syntactic knowledge, thus providing a more complete understanding of students' oral language skills compared to only assessing vocabulary skills.

\section{Word-Based Skills}

Word Reading.-Spanish and English word reading skills were assessed with the LetterWord Identification subtest from the WLPB-R (Woodcock, 1991; Woodcock \& MuñozSandoval, 1995) in Kindergarten, Grade 1, and Grade 2. Children read a list of real words of increasing complexity. Median internal consistency reliability is .91 for Spanish and .92 for English.

Dictation.-Spanish and English writing and spelling skills were assessed with the Dictation subtest from the WLPB-R (Woodcock, 1991; Woodcock \& Muñoz-Sandoval, 1995) in Kindergarten, Grade 1, and Grade 2. The first items measure pre-writing skills such as drawing lines and copying letters. However, the rest of the items are delivered as a traditional dictation spelling test. Median internal consistency reliability is .90 for Spanish and .92 for English. We utilized this measure as it taps children's early literacy skills by requiring that they write and spell words.

\section{Reading Comprehension}

The Reading Comprehension subtest of the Gates MacGinitie Reading Tests (MacGinitie, MacGinitie, Dreyer, \& Hughes, 2000) was used to assess English reading comprehension in Grades 5 and 8. Children are asked to read 13 short passages and answer multiple-choice questions about the passages; this is a timed 35-minute test. Kuder-Richardson Formula 20 reliability is .92 .

\section{Missing Data}

Given the focus on reading comprehension outcomes in Grades 5 and 8, students with reading comprehension data at both Grades 5 and 8 were retained in the analytic sample $(\mathrm{n}=$ 152). Of these students, 4 did not have any data in K-2; these were students who were rerecruited into the study at Grade 5 and had parent interviews on file from study entry, but were never directly assessed in K-2. Thus, the total analytic sample is 148 students. 
Missing data pattern examination revealed that the percent of missing data was $11 \%$ ( $\mathrm{n}=13$ ) in Kindergarten, 14\% $(\mathrm{n}=20)$ in Grade 1, and 18\% $(\mathrm{n}=27)$ in Grade 2. As shown in Appendix A, there were no significant differences in Grade 5 and Grade 8 reading comprehension scores between the sample of students without and with missing data. Multiple imputation was thus conducted with SAS PROC MI analysis using a Markov Chain Monte Carlo estimation with 10 imputations to correct for an unbalanced design and potential biases in the resultant parameter estimates. We then used PROC MIANALYZE to combine the imputations to address our research questions.

\section{Analytic Approach}

Research Question 1: Reading Comprehension Predicted by Single-Year Kindergarten, Grade 1, and Grade 2 Skills.-To address the first research question, linear and quantile regression analyses were conducted using SAS PROC REG and SAS PROC QUANTREG, respectively, controlling for family income and home language use. Separate conventional and quantile regression models were conducted at Grade 5 and 8 to predict whether reading comprehension outcomes relate to Spanish and English languageand word-based skills in Kindergarten, Grade 1, and Grade 2, using the above noted controls. We also examined the autoregressive effect of Grade 5 reading comprehension on Grade 8 reading comprehension outcomes.

\section{Research Question 2: Reading Comprehension Predicted by Averaged K-2}

Skills.-By focusing on average performance in Spanish and English language- and wordbased skills during the primary grade years (i.e., K-2), it may be possible to better explain Spanish-speaking LM learners' English reading comprehension outcomes and more accurately predict reading difficulties through adolescence. To investigate this, students' Spanish and English language- and word-based skills across Kindergarten, Grade 1, and Grade 2 were averaged. We again conducted the linear and quantile regression analyses as outlined in Research Question 1, but now utilized K-2 average performance, controlling for family income and home language use. We again examined the autoregressive effect of Grade 5 reading comprehension on Grade 8 reading comprehension outcomes.

\section{Results}

\section{Home Language Use}

As noted, home language use data was collected during Phase 1 of the study. As shown in Table 1, Pearson correlations revealed a significant and positive correlation between children's averaged language exposure scores and averaged language use scores $(r=.7, \mathrm{p}<$. $001, \mathrm{~N}=148$ ). We thus combining the language exposure and language use scores to arrive at a home language use variable that reflects relative use of Spanish and English for subsequent analyses.

\section{Preliminary Descriptive Analyses}

Table 2 displays students' Spanish and English W-scores (i.e., a developmental scale score), alongside the standard scores, on all measures across all time points. With the exception of English memory for sentences at Grade 2, children's English language-based performance 
fell below the average range from Kindergarten to Grade 2. In sharp contrast, students' English word-based skills were consistently well within the average range from Kindergarten to Grade 2. In Spanish, children's performance on both the language- and word-based measures fell one or more standard deviations below the mean from Kindergarten to Grade 2, with Spanish language-based skills especially depressed. Finally, on English Reading Comprehension, students performed in the low range in Grade 5 (grade level equivalent $=3.7$ ) and in Grade 8 (grade level equivalent $=6.5$ ).

Table 3 displays within-language Pearson correlations among the Spanish and English language- and word-based skills in Kindergarten, Grade 1, and Grade 2. All of the English within-language correlations were significant, ranging from a low of .3 to a high of .8 . Similarly, although with a few exceptions, the Spanish within-language correlations were also significant, ranging from a low of .2 to a high of .9. The generally lower correlations in Spanish were expected given students' English instructional context.

\section{Factor Analysis}

The predictive power of vocabulary and decoding measures on reading comprehension outcomes is well established in the literature, but few studies have utilized verbal short-term memory and dictation measures as predictors of reading comprehension. We thus conducted an exploratory factor analysis to create constructs for use in the subsequent regression analyses. While Kaiser's (1960) "stopping rule" (i.e., selecting eigenvalues of at least 1) is often used to determine the number of factors to be extracted, we adhered by the more theoretically-driven "a priori criterion" (Hair, Anderson, Tatham, \& Black, 1992). Indeed, retaining factors based on the "stopping rule" is considered as one of the least accurate methods given too many factors tend to be retained using this approach (Costello \& Osbourne, 2005; Velicer \& Jackson, 1990). It is recommended that the scree test be utilized, as well as ensuring that at least 3 variables are represented by each factor. Thus, we selected factors with eigenvalues of at least 1 , but on occasion (and explained below) selected fewer factors even when an eigenvalue exceed the 1.0 threshold. We used a promax (oblique) rotation (Tabachnick \& Fidell, 2013) and report the eigenvalues, total variance explained, Kaiser's Measure of Sampling Adequacy, and inter-factor correlations on Tables 4-6.

We began by investigating whether the Spanish and English language- and word-based skills across Kindergarten, Grade 1, and Grade 2 represented language-dependent or languageindependent constructs. Initially, a 5-factor solution emerged, but this solution was unacceptable given that the last 2 factors included only 1 and 2 variables, respectively. We thus explored a 4-factor solution. This solution suggested that students' word- and languagebased skills were language-dependent given that the English language- and word-based skills loaded onto separate factors from the Spanish language- and word-based skills. Given this pattern of results, we next examined a 2-factor solution. As shown in Table 4, a 2-factor solution revealed language-dependence. The only exception was that the Spanish Grade 2 Letter-Word Identification skills did not load onto either factor. We thus expected that the subsequent factor analyses would also reveal language-dependence. 


\section{Language-Based Skills Factor Analysis Results}

Table 5 displays the factor analysis results for the Spanish and English language-based skills in Kindergarten, Grade 1, and Grade 2, separately and averaged across grades. In each grade, a two-factor solution was found, with the English language-based skills loading onto one factor and Spanish language-based skills loading onto another factor. The only exception was for averaged K-2, in which a three-factor solution was initially found. However, we opted for the more theoretically-supported two-factor solution, as the last factor in the 3factor solution only accommodated two variables, Spanish Grade 2 Memory for Sentences and Spanish Grade 2 Picture Vocabulary performance. Further, as shown in Table 6, Spanish Grade 2 Verbal Memory did not surpass the .40 level. However, the scree test clearly indicated a 2 -factor solution.

\section{Word-Based Skills Factor Analysis Results}

Table 6 displays the factor analysis results for the Spanish and English word-based skills in Kindergarten, Grade 1, and Grade 2, separately and averaged across grades. In each grade, a two-factor solution was found, with the English word-based skills loading onto one factor and Spanish word-based skills loading onto another factor. For averaged K-2, although a three-factor solution was found, we opted for the more theoretically-supported 2-factor solution, as the 3-factor solution uniquely accommodated Spanish Grade 2 Letter-Word Identification performance. Further, as shown in Table 6, Spanish Grade 2 Letter-Word Identification did not surpass the .40 level. However, the scree test clearly indicated a 2factor solution.

We then used the language-dependent extracted factors as predictors of students' English reading comprehension outcomes in Grades 5 and 8.

\section{Research Question 1a: Grade 5 Reading Comprehension Predicted by Single-Year Kindergarten, Grade 1, and Grade 2 Skills}

Classical Regression.-As the first column on Table 7 shows, English and Spanish word-based skills in Kindergarten made a statistically significant unique contribution to Grade 5 Reading Comprehension, controlling for the other main effects (English word reading $\beta=9.363107 ; t=3.12 ; p=.0018$; Spanish word reading $\beta=7.126335 ; t=2.32 ; p=$. 0205). By Grade 1, English word-based skills represented the only statistically significant unique contributor to Grade 5 Reading Comprehension, controlling for the other main effects ( $\beta=11.439917 ; t=3.55 ; p=.0004)$. At Grade 2, English word-based skills again represented the only statistically significant unique contributor to Grade 5 Reading Comprehension, controlling for the other main effects $(\beta=18.756663 ; t=6.88 ; p=<.0001)$.

Quantile Regression.-Columns 2-6 on Table 7 show results for quantiles 10, 25, 50, 75, and 90, respectively. In Kindergarten, English word-based skills across all quantiles were significant, Spanish word-based skills were only significant at the $50^{\text {th }}$ and $75^{\text {th }}$ quantiles, and English language comprehension was only significant at the $90^{\text {th }}$ quantile. In Grade 1, English word-based skills across all quantiles, except quantile $90^{\text {th }}$, were significant while Spanish word-based skills were not across any quantile except for quantile 75 . Finally, for Grade 2, only English word-based skills across all quantiles were significant. 


\section{Research Question 1b: Grade 8 Reading Comprehension Predicted by Single-Year Kindergarten, Grade 1, and Grade 2 Skills}

Classical Regression.-Unlike Grade 5 Reading Comprehension, Table 8 shows that early language-based skills emerge as predictive of Grade 8 Reading Comprehension outcomes. In addition to the significance of English and Spanish word-based skills (English word-based skills $\beta=8.228977 ; t=2.74 ; p=.0061$; Spanish word-based skills $\beta=6.772612$; $t=2.23 ; p=.0262$ ), English language-based skills were significant predictors of Grade 8 Reading Comprehension, controlling for the other main effects (English language-based skills $\beta=6.785920 ; t=2.20 ; p=.0280$ ). In Grade 1, English language -based skills remained significant (English language-based skills $\beta=8.498771 ; t=2.72 ; p=.0065)$ and income ( $\beta=$ 8.344980; $t=2.76 ; p=.0058$ ) also made a statistically significant unique contributions to Grade 8 Reading Comprehension, controlling for the other main effects. By Grade 2, only English word- and language-based skills were statistically significant unique contributors to Grade 8 Reading Comprehension, controlling for the other main effects (English word-based skills $\beta=15.753080 ; t=6.18 ; p=<.0001$; English language-based skills $\beta=8.112304 ; t=$ $3.00 ; p=<.0028)$.

Additionally, the last column of Table 8 displays the results controlling for the autoregressive effect of Grade 5 Reading Comprehension. In Kindergarten and Grade 1, income makes a significant contribution to Grade 8 Reading Comprehension, but languagebased skills emerge as significant in Grades 1 and 2. Of note, the prediction of English word-based skills attenuates, expect in Grade 2.

Quantile Regression.-Columns 2-6 on Table 8 show results for quantiles 10, 25, 50, 75, and 90, respectively. In Kindergarten, only English and Spanish word-based skills in the inter-quartile range are significant. However, in Grade 1 and except for the lowest quartile, English language-based skills across all quartiles are significant while Spanish word-based skills in the inter-quartile range are significant. Finally, in Grade 2, English word-based skills across all quantiles were significant while English language-based skills at the $50^{\text {th }}$ and $75^{\text {th }}$ quantiles are significant.

\section{Research Question 2a: Grade 5 Reading Comprehension Predicted by Averaged K-2 Skills \\ Classical Regression.-As the first column on Table 7 shows, only the averaged K-2 English word-based skills made a statistically significant unique contribution to Grade 5 Reading Comprehension, controlling for the other main effects ( $\beta=14.770834 ; t=4.10 ; p=$ $<.0001)$.}

Quantile Regression.-Columns 2-6 on Table 7 show results for quantiles 10, 25, 50, 75, and 90, respectively. English word-based skills emerged as the unique robust predictor of Grade 5 Reading Comprehension across all quantiles, while English language comprehension was only significant at the $90^{\text {th }}$ quantile.

\section{Research Question 2a: Grade 8 Reading Comprehension Predicted by Averaged K-2 Skills}

Classical Regression.-As the first column on Table 8 shows, the averaged K-2 English word-and language-based skills made statistically significant unique contributions to Grade 
8 Reading Comprehension, controlling for the other main effects (English word-based skills $\beta=9.585907 ; t=2.66 ; p=.0079$; English language-based skills $\beta=9.073497 ; t=2.61 ; p=$. 0092).

Additionally, the last column of Table 8 displays the results controlling for the autoregressive effect of Grade 5 Reading Comprehension. Now only language-based skills and income make a significant contribution to Grade 8 Reading Comprehension.

Quantile Regression.-Columns 2-6 on Table 8 show results for quantiles 10, 25, 50, 75, and 90, respectively. For both the English word- and language-based skills, the interquartile range was significant.

\section{Discussion}

There is wide consensus about the importance of preventing children's reading comprehension difficulties. Despite LM learners' widespread reading challenges, generating an early "at-risk" identification for later reading comprehension difficulties among this population of learners is a complex undertaking. The four key findings from this study provide unique insight into early determinants of reading comprehension for Spanishspeaking LM learners at two distinct points in development (i.e., $5^{\text {th }}$ and $8^{\text {th }}$ grade). First, we found a developmental shift in the contribution of language- and word-based skills on students' reading comprehension outcomes. Specifically, word-based skills represented the single robust predictor of Grade 5 reading comprehension outcomes, but language-based skills emerged as consequential for Grade 8 reading comprehension. Second, Grade 5 reading comprehension outcomes were predicted roughly equally whether indexed by single-year Kindergarten, Grade 1, or Grade 2 skills or whether averaged across the K-2 years. However, Grade 8 reading comprehension outcomes were not as reliably predicted by students' Kindergarten skills. Third, for this sample of learners, classical regression generally captured the relationship between students' word- and language-based skills and their reading comprehension outcomes in Grade 5, but a quantile regression approach appeared to provide added insight into Grade 8 reading comprehension outcomes. Finally, and as expected given students' English-only instructional context, Spanish skills were not robust, consistent predictors of students' English reading comprehension outcomes at either point in development. Below, we discuss each of these findings in more detail, with attention to the theoretical and practical implications of this work.

\section{A Developmental Shift in the Prediction of Language Comprehension Skills}

To our knowledge, this is the first study to document a developmental shift in the prediction of language comprehension on reading comprehension outcomes among Spanish-speaking LM learners; the emerging relation of early English language-based skills on Grade 8 English reading comprehension outcomes is arguably the most theoretically and practically informative finding derived from the study. Had reading comprehension outcomes among this sample of Spanish-speaking LM learners from low-income homes been predicted only at Grade 5, the conclusion would have been that language-based skills do not predict their reading comprehension outcomes once word-based skills are accounted for. However, the longitudinal design of our study allowed for a continued investigation of this group's reading 
comprehension performance at the end of Grade 8. It was at this distinct point in development that a different picture emerged, such that early language-based skills were found to be consequential for reading comprehension outcomes at the end of the middle school years. Indeed, this finding held when accounting for the autoregressive effect of Grade 5 reading comprehension in predicting Grade 8 reading comprehension outcomes. This finding has important theoretical and practical implications for understanding and targeting the reading comprehension needs of LM learners.

Theoretically, and as suggested by Mancilla-Martinez and Lesaux (2011), it appears that development shifts can be expected once students have acquired age-appropriate reading comprehension skills. In this sample, students' Grade 5 reading comprehension skills were equivalent to that of a mid-year Grade 3 student while their Grade 8 reading comprehension skills were equivalent to that of a mid-year Grade 6 student; in both cases, students' reading comprehension skills fell roughly two grade levels below expectations. In our view, the Grade 5 reading comprehension model reflects a model of comprehension once thought to be for primary grade readers - wherein we expect word-based skills to be most predictive. But the Grade 8 reading comprehension model reflects a model of comprehension for adolescent students wherein language-based skills are indeed expected to contribute unique variance.

Practically, our findings underscore the importance of supporting Spanish-speaking LM learners' English language-based skills immediately upon formal school entry in the service of supporting their later English reading comprehension outcomes. Other researchers (August, Carlo, Dressler, \& Snow, 2005; Mancilla-Martinez \& Lesaux, 2010) have reached this conclusion, but the specificity of the evidence generated from this study makes this call all the more pressing. Indeed, our results align with recent work by Savage, Kozakewich, Genesee, Haigh, and Erdos (2017) who found that early (grade 1) language screening of English-French bilingual students in the primary grades predicted later (grade 6) writing outcomes, suggesting that language development instruction may represent a promising mechanism by which to support reading and writing outcomes among bilingual learners.

\section{Early Reading Screening is Crucial}

Our second finding informs the timing of early screening batteries for Spanish-speaking LM learners. We investigated the relation of single-year (i.e., Kindergarten, Grade 1, and Grade 2) Spanish and English language- and word-based skills on English reading comprehension outcomes in Grade 5 and 8, and also investigated the relation of students' K-2 performance average across these years on these same outcomes. While performance in a given single primary grade year predicted Grade 5 reading outcomes about equally, performance either across the primary grade years or in Grades 1 or 2 represented a more robust mechanism for predicting students' Grade 8 outcomes. Our results suggest that caution should be exercised when evaluating Spanish-speaking LM learners' Kindergarten language-based skills as predictors of reading outcomes in adolescence, possibly related to the fact that students' English language skills were in the early stages of development. 


\section{How We Predict Reading Comprehension among LM Learners Might Matter for Understanding the Role of Early Predictors}

Our third finding must be interpreted with caution given the relatively small sample size in this study (Petscher \& Logan, 2013), but is nevertheless worthy of discussion and, in turn, further study. The finding suggests that the prediction of English word-based skills is more or less equivalent across the distribution of Grade 5 English reading comprehension performance. English word-based skills emerged as significant across nearly all of the English reading comprehension quantiles in Kindergarten, Grade 1, Grade 2, and across the $\mathrm{K}-2$ average. This suggests that a classical regression approach likely provides an adequate estimate of Grade 5 English reading comprehension outcomes. However, a somewhat different picture emerged for Grade 8 English reading comprehension. In this case, English word-based skills were only significant across all quantiles in Grade 2, suggesting that the prediction of students' early English word-based skills tended to vary depending on students' Grade 8 English reading comprehension levels. Additionally, the prediction of English language-based skills appeared to vary depending on students' Grade 8 reading comprehension levels, and generally emerged as more significant at the upper quartiles. Specifically, we found no prediction of language-based skills in Kindergarten, Grade 1, Grade 2, or across the K-2 average at the lowest end of the Grade 8 English reading comprehension distribution (i.e., the $10^{\text {th }}$ quantile). Furthermore, the prediction of languagebased skills emerged after Kindergarten. Finally, the role of Spanish word-based skills warrants attention. For both Grade 5 and Grade 8 English reading comprehension, Spanish word-based skills in Kindergarten consistently emerged as significant, but it is difficult to specify whether the nature of the relationship held more robustly across specific quantiles in the reading comprehension distribution. More work with larger samples is needed to confirm the extent to which the trends we found hold, but our results suggest that it is advisable to continue investigations of the relationship between early component skills and subsequent reading comprehension outcomes beyond the average relation and across the distribution of reading comprehension performance.

\section{An English Model of Reading Comprehension}

Finally, and expected given students' English-only instructional contexts, early Spanish language- and word-based skills did not exert a consistent and sustained relation on later English reading comprehension outcomes, once English skills were taken into account. This finding converges with other work in this area as Spanish skills typically do not uniquely contribute to English reading comprehension outcomes (e.g., Lindsey, Manis, \& Bailey, 2003; Manis, Lindsey, \& Bailey 2004; Mancilla-Martinez \& Lesaux, 2010). An exception is the work of Proctor and colleagues (2006), whose sample received formal Spanish literacy instruction, likely helping to explain the small but significant cross-language effects.

Nonetheless, the relation of Spanish skills cannot be completely dismissed. Kindergarten Spanish word-based skills contributed to both Grade 5 and Grade 8 English reading comprehension outcomes. It is possible that the Kindergarten word-based skills represent a proxy for students' early home literacy environment, but further work is needed to explore this. We also underscore that we accounted for students' income and home language status in all models to obtain unbiased estimates. However, our sample did not vary widely on income status, with the majority living in or near poverty, and also did not differ widely on 
their reported home language use, with the majority using notable amounts of Spanish. Thus, it was not unexpected that neither income nor home language emerged as unique contributors of students' English reading comprehension outcomes.

\title{
Limitations and Future Research
}

This study focused on U.S.-born children of immigrants from Spanish-speaking, low-income homes educated in English-only instructional contexts, requiring that the demographics of this group be considered when interpreting the results. Also, the measures used in this study were designed for and normed on monolinguals, either native English or native Spanish speakers. However, like most students from non-native English-speaking homes in the U.S., students in the sample negotiated two languages beginning prior to formal school entry. Language-based measures, including those that tap the discourse level, that are designed for this population of learners might well provide more accurate insight language skills and better predict future reading comprehension outcomes. On a similar vein, two of the measures used (Memory for Sentences and Dictation from the WLPB-R; Woodcock, 1991; Woodcock \& Muñoz-Sandoval, 1995) are not widely used in the field and their use as predictors of reading comprehension warrant future investigation. Furthermore, because this study was designed to examine developmental trends in Spanish-speaking LM learners' language- and word-based skills, a measure of general intellectual ability was not included and such a measure could potentially further help explain the extent to which the relation of early language- and word-based skills on later RC outcomes varies by general intellectual ability. We also underscore that, as previously noted, caution must be exercised when interpreting the quantile regression results given our sample size. Finally, while we included the auto-regressive effect of Grade 5 reading comprehension on Grade 8 reading comprehension outcomes, we did not have an analogous auto-regressor in predicting Grade 5 reading comprehension. Thus, the associations between the early language- and wordbased skills to later reading comprehension should not be interpreted as causal.

Results of our study underscore the need for primary grade screening batteries that attend to word-based measures (as has typically been the case), but that also include language-based measures (which are most often omitted, see Catts et al., 2014 for a discussion). Indeed, our results underscore the increasingly important role that early language-based skills play for later English reading comprehension outcomes. If we are to narrow the persistent reading achievement gap between English-only and LM learners, future research must focus on investigating how best to provide this language-based support beginning in the primary grade years. Such research should examine in particular the ways in which language-based instruction should be adapted across the formal school years to be both developmentally appropriate and aligned to the increasing language and cognitive demands of text.

\section{Acknowledgments}

\author{
Funding \\ National Institute of Child Health and Human Development; Spencer Foundation
}




\section{Appendix A}

Sample mean, standard deviation and statistics testing for differences in Grade 5 and Grade 8 raw reading comprehension ( $\mathrm{RC}$ ) scores for students without and with missing data on the Spanish and English language- and word-based skills in Kindergarten, Grade 1 and Grade 2.

\begin{tabular}{|c|c|c|c|c|}
\hline \multirow[t]{2}{*}{ Grade Level } & \multicolumn{2}{|c|}{ Mean (SD) } & \multicolumn{2}{|c|}{ F statistic and p-values } \\
\hline & Grade 5 RC & Grade 8 RC & Raw & Bonferroni \\
\hline \multicolumn{5}{|l|}{ Kindergarten } \\
\hline No Missing Data $(\mathrm{n}=135)$ & $19.04(8.69)$ & $24.85(9.84)$ & $\begin{array}{c}F(1,146)=0.17 \\
p=0.68\end{array}$ & 1.00 \\
\hline Missing Data $(\mathrm{n}=13)$ & $18.00(8.69)$ & $23.46(10.86)$ & $\mathrm{F}(1,146)=0.23$ & 1.00 \\
\hline Grade 1 & & & $\mathrm{p}=0.63$ & \\
\hline No Missing Data $(\mathrm{n}=128)$ & $19.16(8.95)$ & $24.88(9.95)$ & $\begin{aligned} \mathrm{F}(1,146) & =0.52, \mathrm{p}=0.47 \\
\mathrm{p} & =0.47\end{aligned}$ & 0.94 \\
\hline $\begin{array}{l}\text { Missing Data }(\mathrm{n}=20) \\
\text { Grade } 2\end{array}$ & $17.65(6.54)$ & $23.80(9.79)$ & $\begin{array}{c}F(1,146)=0.20 \\
p=0.65\end{array}$ & 1.00 \\
\hline No Missing Data $(\mathrm{n}=121)$ & $19.19(8.90)$ & $25.03(10.16)$ & $\begin{array}{c}F(1,146)=0.50 \\
p=0.48\end{array}$ & 0.96 \\
\hline Missing Data $(\mathrm{n}=27)$ & $17.89(7.56)$ & $23.37(8.70)$ & $\begin{array}{c}F(1,146)=0.62 \\
p=0.43\end{array}$ & 0.86 \\
\hline
\end{tabular}

\section{References}

August D, Carlo M, Dressler C, \& Snow C (2005). The critical role of vocabulary development for English language learners. Learning Disabilities Research and Practice, 20(1), 50-57.

Cárdenas-Hagan E, Carlson CD, \& Pollard-Durodola SD (2007). The cross-linguistic transfer of early literacy skills: The role of initial L1 and L2 skills and language of instruction. Language, Speech \& Hearing Services in Schools, 38(3), 249-259.

Catts HW, Adlof SM, \& Weismer SE (2006). Language deficits in poor comprehenders: A case for the simple view of reading. Journal of Speech, Language, and Hearing Research, 49(2), 278-293.

Catts HW, Fey ME, Zhang X, \& Tomblin JB (2001). Estimating the risk of future reading difficulties in kindergarten children: A research-based model and its clinical implementation. Language, Speech, and Hearing Services in Schools, 32(1), 38-50.

Catts HW, Hogan TP, \& Adlof SM (2005). Developmental changes in reading and reading disabilities In Catts HW \& Kamhi AG (Eds.), The connections between language and reading disabilities (pp. 25-40). Mahwah, NJ: Lawrence Erlbaum Associates.

Catts HW, Nielsen DC, Bridges MS, \& Liu Y (2014). Early identification of reading comprehension difficulties. Journal of Learning Disabilities, 49(5) 451-465. [PubMed: 25344060]

Costello AB, \& Osborne JW (2005). Best practices in exploratory factor analysis: Four recommendations for getting the most from your analysis. Practical Assessment, Research \& Evaluation, 10(7), 1-9.

Durgunoglu AY, Nagy WE, \& Hancin-Bhatt BJ (1993). Cross-language transfer of phonological awareness. Journal of Educational Psychology, 85(3), 453-465.

Gough PB, \& Tunmer WE (1986). Decoding, reading and reading disability. Remedial and Special Education, 7(1), 6-10.

Hair JF, Anderson RE, Tatham RL, \& Black WC (1992). Multivariate data analysis with readings (3rd ed.). New York: Macmillan. 
Hammer CS, Hoff E, Uchikoshi Y, Gillanders C, Castro DC, \& Sandilos LE (2014). The language and literacy development of young dual language learners: A critical review. Early Childhood Research Quarterly, 29(4), 715-733. [PubMed: 25878395]

Hoover WA, \& Gough PB (1990). The simple view of reading. Reading and Writing: An Interdisciplinary Journal, 2(2), 127-160.

Johnston TC, \& Kirby JR (2006). The contribution of naming speed to the simple view of reading. Reading and Writing. An Interdisciplinary Journal, 19(4), 339-361.

Kaiser HF (1960). The application of electronic computers to factor analysis. Educational and Psychological Measurement, 20(1), 141-151.

Koenker R, \& Bassett G (1978). Regression quantiles. Econometrica, 46(1), 33-50.

Lindsey K, Manis FR, \& Bailey CE (2003). Prediction of first-grade reading in Spanish- speaking English-language learners. Journal of Educational Psychology, 95(3), 482-494.

McCardle P, Mele-McCarthy J, Cutting L, Leos K, \& D’Emilio T (2005). Learning disabilities in English language learners: Identifying the issues. Learning Disabilities Research and Practice, 20(1), 1-5.

MacGinitie WH, MacGinitie RK, Maria K, Dreyer LG, \& Hughes KE (2000). Gates-MacGinitie Reading Tests (GMRT) Fourth Edition. Rolling Meadows: Riverside.

Mancilla-Martinez J, \& Lesaux NK (2010). Predictors of reading comprehension for struggling readers: The case of Spanish-speaking language minority learners. Journal of Educational Psychology, 102(3), 701-711. [PubMed: 20856691]

Mancilla-Martinez J, \& Lesaux NK (2011). The gap between Spanish-Speakers' word reading and word knowledge: A longitudinal study. Child Development, 82(5), 1544-1560. [PubMed: 21848955]

Mancilla-Martinez J, \& Vagh SB (2013). Growth in toddlers' Spanish, English, and conceptual vocabulary knowledge. Early Childhood Research Quarterly, 28 (3), 555-567.

Manis FR, Lindsey KA, \& Bailey CE (2004). Development of reading in grades K-2 in Spanishspeaking English-language learners. Learning Disabilities Research and Practice, 19(4), 214-224.

Melby-Lervåg M, \& Lervåg A (2011). Cross-linguistic transfer of oral language, decoding, phonological awareness and reading comprehension; a meta-analysis of the correlational evidence. Journal of Research in Reading, 34(1), 114-135.

Murphey D, Guzman L, \& Torres A (2014). America's Hispanic children: Gaining ground, looking forward. Retrieved from http://www.childtrends.org/wp-content/uploads/ 2014/09/2014-38AmericaHispanicChildren.pdf

Nakamoto J, Lindsey KA, \& Manis FR (2008). A cross-linguistic investigation of English language learners' reading comprehension in English and Spanish. Scientific Studies of Reading, 12(4), 351-371.

Olson RK, Keenan JM, Byrne B, Samuelsson S, Coventry WL, Corley R, Wadsworth SJ, Willcutt EG, DeFries JC, Pennington BF, \& Hulslander J (2011). Genetic and environmental influences on vocabulary and reading development. Scientific Studies of Reading, 15(1), 26-46. [PubMed: 21132077]

Perfetti C (2007). Reading ability: Lexical quality to comprehension. Scientific Studies of Reading, 11(4), 357-383.

Petscher Y, \& Logan JAR (2014). Quantile regression in the study of developmental sciences. Child Development, 85(3), 861-881. [PubMed: 24329596]

Proctor CP, Carlo M, August D, \& Snow C (2005). Native Spanish-speaking children reading in English: Toward a model of comprehension. Journal of Educational Psychology, 97(2), 246-256.

Proctor CP, August D, Carlo M, \& Snow C (2006). The intriguing role of Spanish vocabulary knowledge in predicting English reading comprehension. Journal of Educational Psychology, 98(1), 159-169.

Savage RS, Kozakewich M, Genesee F, Haigh C \& Erdos C (2017). Predicting writing development in dual language instructional contexts: Exploring cross-linguistic relationships. Developmental Science, 20(1), 1-13. DOI: 10.1111/desc.12406 
Schatschneider C, Fletcher JM, Francis DJ, Carlson CD, \& Foorman BR (2004). Kindergarten prediction of reading skills: A longitudinal comparative analysis. Journal of Educational Psychology, 96(2), 265-282.

Snow CE, Burns S, \& Griffin P (1998). Preventing reading difficulties in young children. Washington, DC: National Academy Press.

Stevens RJ, Lu X, Baker DP, Ray MN, Eckert SA, \& Gamson DA (2015). Assessing the cognitive demands of a century of reading curricula: An analysis of reading text and comprehension tasks from 1910 to 2000. American Educational Research Journal, 52(3), 582-617.

Tabachnick BG, \& Fidell LS (2013). Using Multivariate Statistics, 6th ed. Boston: Pearson.

Torgesen JK (2002). The prevention of reading difficulties. Journal of School Psychology, 40(1), 7-26.

U.S. Census Bureau (2001). Poverty thresholds 2001. Retrieved from https://www.census.gov/data/ tables/time-series/demo/income-poverty/ historical-poverty-thresholds.html

Velicer WF, \& Jackson DN (1990). Component analysis versus common factor-analysis: some further observations. Multivariate Behavioral Research, 25(1), 97-114. [PubMed: 26741975]

Vellutino FR, Tunmer WE, Jaccard JJ, Chen R (2007). Components of reading ability: Multivariate evidence for a convergent skills model of reading development. Scientific Studies of Reading, 11(1), 3-32.

Woodcock RW (1991). Woodcock Language Proficiency Battery- Revised. Itasca, IL: Riverside Publishing.

Woodcock RW, \& Munoz-Sandoval AF (1995). Bateria Woodcock-Munoz Pruebas de Aprovechamieto- Evisada. Chicago: Riverside. 


\section{Table 1}

Patterns of Language Exposure to Child and Language Use by Child with All Household Members at Child Age 4.5, and Spearman Correlation between Language Exposure and Use

\begin{tabular}{|c|c|c|c|c|}
\hline & Mostly Spanish & Equal Amounts & Mostly English & $r^{ \pm}$ \\
\hline Input by mother to child & $74 \%$ & $20 \%$ & $8 \%$ & \\
\hline$(\mathrm{n}=143)$ & $(n=104)$ & $(\mathrm{n}=28)$ & $(\mathrm{n}=11)$ & \\
\hline Output by child to mother & $52 \%$ & $17 \%$ & $31 \%$ & .7 \\
\hline$(n=143)$ & $(\mathrm{n}=75)$ & $(\mathrm{n}=24)$ & $(\mathrm{n}=44)$ & \\
\hline Input by father to child & $65 \%$ & $17 \%$ & $18 \%$ & \\
\hline$(\mathrm{n}=100)$ & $(\mathrm{n}=65)$ & $(\mathrm{n}=17)$ & $(\mathrm{n}=18)$ & \\
\hline Output by child to father & $52 \%$ & $13 \%$ & $35 \%$ & .7 \\
\hline$(\mathrm{n}=100)$ & $(\mathrm{n}=52)$ & $(\mathrm{n}=13)$ & $(\mathrm{n}=35)$ & \\
\hline Input by other adults to child & $73 \%$ & $17 \%$ & $12 \%$ & \\
\hline$(\mathrm{n}=117)$ & $(\mathrm{n}=85)$ & $(\mathrm{n}=20)$ & $(\mathrm{n}=14)$ & \\
\hline Output by child to other adults & $64 \%$ & $15 \%$ & $21 \%$ & .6 \\
\hline$(\mathrm{n}=117)$ & $(\mathrm{n}=75)$ & $(\mathrm{n}=18)$ & $(\mathrm{n}=24)$ & \\
\hline Input by other children to child & $27 \%$ & $25 \%$ & $48 \%$ & \\
\hline$(\mathrm{n}=124)$ & $(\mathrm{n}=33)$ & $(\mathrm{n}=31)$ & $(\mathrm{n}=60)$ & \\
\hline Output by child to other children & $28 \%$ & $25 \%$ & $47 \%$ & .7 \\
\hline$(\mathrm{n}=124)$ & $(\mathrm{n}=35)$ & $(\mathrm{n}=31)$ & $(\mathrm{n}=58)$ & \\
\hline Overall language exposure & $48 \%$ & $43 \%$ & $8 \%$ & \\
\hline$(n=148)$ & $(\mathrm{n}=72)$ & $(\mathrm{n}=63)$ & $(\mathrm{n}=13)$ & \\
\hline Overall language use & $47 \%$ & $29 \%$ & $24 \%$ & .7 \\
\hline$(n=148)$ & $(\mathrm{n}=69)$ & $(n=43)$ & $(\mathrm{n}=36)$ & \\
\hline
\end{tabular}

${ }^{ \pm}$All p-values $<.001$ 


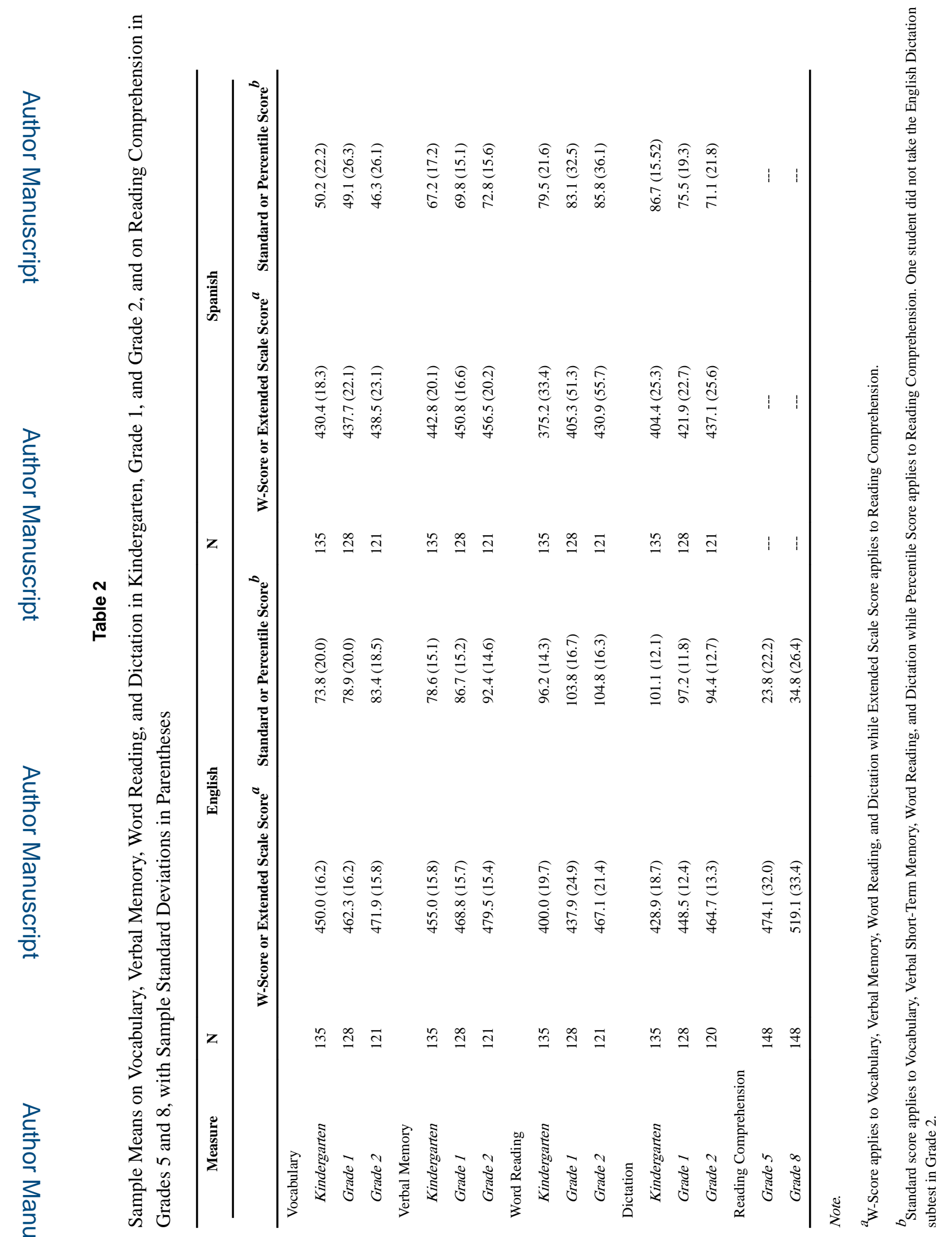

Sci Stud Read. Author manuscript; available in PMC 2019 September 11. 


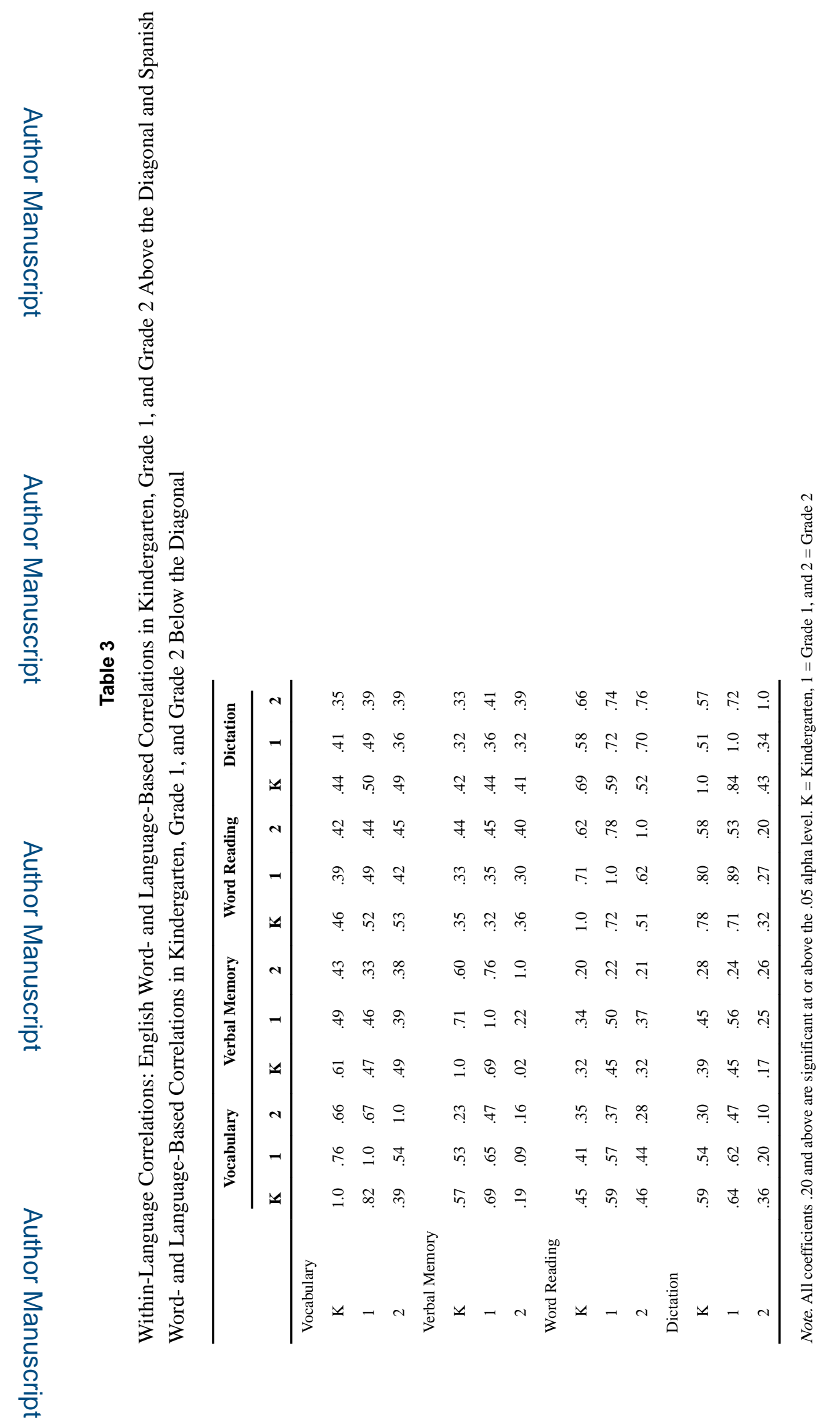

Sci Stud Read. Author manuscript; available in PMC 2019 September 11. 


\section{Table 4}

Factor loadings for principal components analysis using promax rotation on the Spanish and English Wordand Language-Based Skills in Kindergarten, Grade 1, and Grade 2

\begin{tabular}{|l|c|c|}
\hline & $\begin{array}{c}\text { Factor 1: } \\
\text { English Skills }\end{array}$ & $\begin{array}{c}\text { Factor 2: } \\
\text { Spanish Skills }\end{array}$ \\
\hline Spanish Kinder Vocabulary & & $\mathbf{. 6 6}$ \\
\hline Spanish Grade 1 Vocabulary & & $\mathbf{. 8 5}$ \\
\hline Spanish Grade 2 Vocabulary & & $\mathbf{. 4 1}$ \\
\hline Spanish Kinder Verbal Memory & & $\mathbf{. 6 1}$ \\
\hline Spanish Grade 1 Verbal Memory & & $\mathbf{. 7 7}$ \\
\hline Spanish Grade 2 Verbal Memory & & $\mathbf{. 3 5}$ \\
\hline Spanish Kinder Letter-Word ID & & $\mathbf{. 7 2}$ \\
\hline Spanish Grade 1 Letter-Word ID & & $\mathbf{. 8 6}$ \\
\hline Spanish Grade 2 Letter-Word ID & & \\
\hline Spanish Kinder Dictation & &. .66 \\
\hline Spanish Grade 1 Dictation & & $\mathbf{. 8 7}$ \\
\hline Spanish Grade 2 Dictation & & $\mathbf{. 4 9}$ \\
\hline English Kinder Vocabulary & $\mathbf{. 8 1}$ & \\
\hline English Grade 1 Vocabulary & $\mathbf{. 8 5}$ & \\
\hline English Grade 2 Vocabulary & $\mathbf{. 7 8}$ & \\
\hline English Kinder Verbal Memory & $\mathbf{. 6 4}$ & \\
\hline English Grade 1 Verbal Memory & $\mathbf{. 6 9}$ & \\
\hline English Grade 2 Verbal Memory & $\mathbf{. 6 3}$ & \\
\hline English Kinder Letter-Word ID & $\mathbf{. 8 6}$ & \\
\hline English Grade 1 Letter-Word ID & $\mathbf{. 7 3}$ & \\
\hline English Grade 2 Letter-Word ID & $\mathbf{. 6 9}$ & \\
\hline English Kinder Dictation & $\mathbf{. 7 7}$ & \\
\hline English Grade 1 Dictation & $\mathbf{. 7 3}$ & \\
\hline English Grade 2 Dictation & $\mathbf{. 6 9}$ & \\
\hline Eigenvalues & 8.05 & \\
\hline Total Variance Explained & & \\
\hline Kaiser's MSA * & & \\
\hline Inter-Factor Correlation & & \\
\hline
\end{tabular}

Note. Only loadings above .40 are displayed

MSA = Measure of Sampling Adequacy 


\section{Table 5}

Factor loadings for principal components analysis using promax rotation on the Spanish and English Language-Based Skills in Kindergarten, Grade 1, and Grade 2, Separately by Grade and Averaged Across Grades

\begin{tabular}{|c|c|c|}
\hline & Factor 1: English Kinder Language-Level Skills & Factor 2: Spanish Kinder Language-Level Skills \\
\hline Spanish Vocabulary & & .88 \\
\hline Spanish Verbal Memory & & .86 \\
\hline English Vocabulary & .89 & \\
\hline English Verbal Memory & .87 & \\
\hline Eigenvalues & 1.67 & 1.50 \\
\hline Total Variance Explained & \multicolumn{2}{|c|}{$79 \%$} \\
\hline Kaiser's MSA* & \multicolumn{2}{|c|}{.50} \\
\hline \multirow[t]{2}{*}{ Inter-Factor Correlation } & \multicolumn{2}{|c|}{.05} \\
\hline & Factor 1: Spanish Grade 1 Language-Level Skills & $\begin{array}{c}\text { Factor 2: English Grade } 1 \text { Language-Level } \\
\text { Skills }\end{array}$ \\
\hline Spanish Vocabulary & .88 & \\
\hline Spanish Verbal Memory & .92 & \\
\hline English Vocabulary & & .88 \\
\hline English Verbal Memory & & .83 \\
\hline Eigenvalues & 1.82 & 1.44 \\
\hline Total Variance Explained & \multicolumn{2}{|c|}{$81 \%$} \\
\hline Kaiser's MSA * & \multicolumn{2}{|c|}{.41} \\
\hline \multirow[t]{2}{*}{ Inter-Factor Correlation } & \multicolumn{2}{|c|}{.07} \\
\hline & Factor 1: English Grade 2 Language-Level Skills & $\begin{array}{c}\text { Factor 2: Spanish Grade } 2 \text { Language-Level } \\
\text { Skills }\end{array}$ \\
\hline Spanish Vocabulary & & .86 \\
\hline Spanish Verbal Memory & & .63 \\
\hline English Vocabulary & .84 & \\
\hline English Verbal Memory & .79 & \\
\hline Eigenvalues & 1.53 & 1.08 \\
\hline Total Variance Explained & 65 & \\
\hline Kaiser's MSA * & $\therefore$ & \\
\hline \multirow[t]{2}{*}{ Inter-Factor Correlation } & \multicolumn{2}{|c|}{-.09} \\
\hline & Factor 1: English K-2 Language-Level Skills & Factor 2: Spanish K-2 Language-Level Skills \\
\hline Spanish Kinder Vocabulary & & .86 \\
\hline Spanish Grade 1 Vocabulary & & .86 \\
\hline Spanish Grade 2 Vocabulary & & .44 \\
\hline Spanish Kinder Verbal Memory & & .74 \\
\hline Spanish Grade 1 Verbal Memory & & .88 \\
\hline Spanish Grade 2 Verbal Memory & & \\
\hline
\end{tabular}




\begin{tabular}{|l|c|c|}
\hline & Factor 1: English Kinder Language-Level Skills & Factor 2: Spanish Kinder Language-Level Skills \\
\hline English Kinder Vocabulary & $\mathbf{. 8 6}$ & \\
\hline English Grade 1 Vocabulary & $\mathbf{. 8 3}$ & \\
\hline English Grade 2 Vocabulary & $\mathbf{. 8 0}$ & \\
\hline English Kinder Verbal Memory & $\mathbf{. 7 9}$ & \\
\hline English Grade 1 Verbal Memory & $\mathbf{. 8 0}$ & \\
\hline English Grade 2 Verbal Memory & $\mathbf{. 7 2}$ & 3.2 \\
\hline Eigenvalues & 4.1 & $61 \%$ \\
\hline Total Variance Explained & & .76 \\
\hline Kaiser's MSA * & \multicolumn{2}{|c|}{.13} \\
\hline Inter-Factor Correlation & \multicolumn{2}{|c|}{} \\
\hline
\end{tabular}

Note. Only loadings above .40 are displayed

MSA = Measure of Sampling Adequacy 


\section{Table 6}

Factor loadings for principal components analysis using promax rotation on the Spanish and English WordBased Skills in Kindergarten, Grade 1, and Grade 2, Separately by Grade and Averaged Across Grades

\begin{tabular}{|c|c|c|}
\hline & Factor 1: Spanish Kinder Word-Level Skills & Factor 2: English Kinder Word-Level Skills \\
\hline Spanish Letter-Word ID & .90 & \\
\hline Spanish Dictation & .91 & \\
\hline English Letter-Word ID & & .90 \\
\hline English Dictation & & .91 \\
\hline Eigenvalues & 1.97 & 1.32 \\
\hline Total Variance Explained & \multicolumn{2}{|c|}{$82 \%$} \\
\hline Kaiser's MSA * & \multicolumn{2}{|c|}{.49} \\
\hline \multirow[t]{2}{*}{ Inter-Factor Correlation } & \multicolumn{2}{|c|}{.19} \\
\hline & Factor 1: Spanish Grade 1 Word-Level Skills & Factor 2: English Grade 1 Word-Level Skills \\
\hline Spanish Letter-Word ID & .96 & \\
\hline Spanish Dictation & .97 & \\
\hline English Letter-Word ID & & .90 \\
\hline English Dictation & & .96 \\
\hline Eigenvalues & 2.51 & 1.13 \\
\hline Total Variance Explained & \multicolumn{2}{|c|}{$91 \%$} \\
\hline Kaiser's MSA * & \multicolumn{2}{|c|}{.58} \\
\hline \multirow[t]{2}{*}{ Inter-Factor Correlation } & \multicolumn{2}{|c|}{36} \\
\hline & Factor 1: English Grade 2 Word-Level Skills & Factor 2: Spanish Grade 2 Word-Level Skills \\
\hline Spanish Letter-Word ID & & .91 \\
\hline Spanish Dictation & & .48 \\
\hline English Letter-Word ID & .93 & \\
\hline English Dictation & .91 & \\
\hline Eigenvalues & 1.86 & 1.02 \\
\hline Total Variance Explained & & \\
\hline Kaiser's MSA * & & \\
\hline \multirow[t]{2}{*}{ Inter-Factor Correlation } & \multicolumn{2}{|c|}{.05} \\
\hline & Factor 1: English K-2 Word-Level Skills & Factor 2: Spanish K-2 Word-Level Skills \\
\hline Spanish Kinder Letter-Word ID & & .82 \\
\hline Spanish Grade 1 Letter-Word ID & & .93 \\
\hline \multicolumn{3}{|l|}{ Spanish Grade 2 Letter-Word ID } \\
\hline Spanish Kinder Dictation & & .81 \\
\hline Spanish Grade 1 Dictation & & .91 \\
\hline Spanish Grade 2 Dictation & & .59 \\
\hline English Kinder Letter-Word ID & .95 & \\
\hline English Grade 1 Letter-Word ID & .83 & \\
\hline
\end{tabular}




\begin{tabular}{|l|c|c|}
\hline & Factor 1: Spanish Kinder Word-Level Skills & Factor 2: English Kinder Word-Level Skills \\
\hline English Grade 2 Letter-Word ID & $\mathbf{. 6 7}$ & \\
\hline English Kinder Dictation & $\mathbf{. 4}$ & \\
\hline English Grade 1 Dictation & $\mathbf{. 8 7}$ & \\
\hline English Grade 2 Dictation & $\mathbf{. 8 2}$ & \\
\hline Eigenvalues & 5.55 & $66 \%$ \\
\hline Total Variance Explained & \multicolumn{2}{|c|}{.86} \\
\hline Kaiser's MSA * & \multicolumn{2}{|c|}{.39} \\
\hline Inter-Factor Correlation & \multicolumn{2}{|c|}{} \\
\hline
\end{tabular}

Note. Only loadings above .40 are displayed

MSA = Measure of Sampling Adequacy 


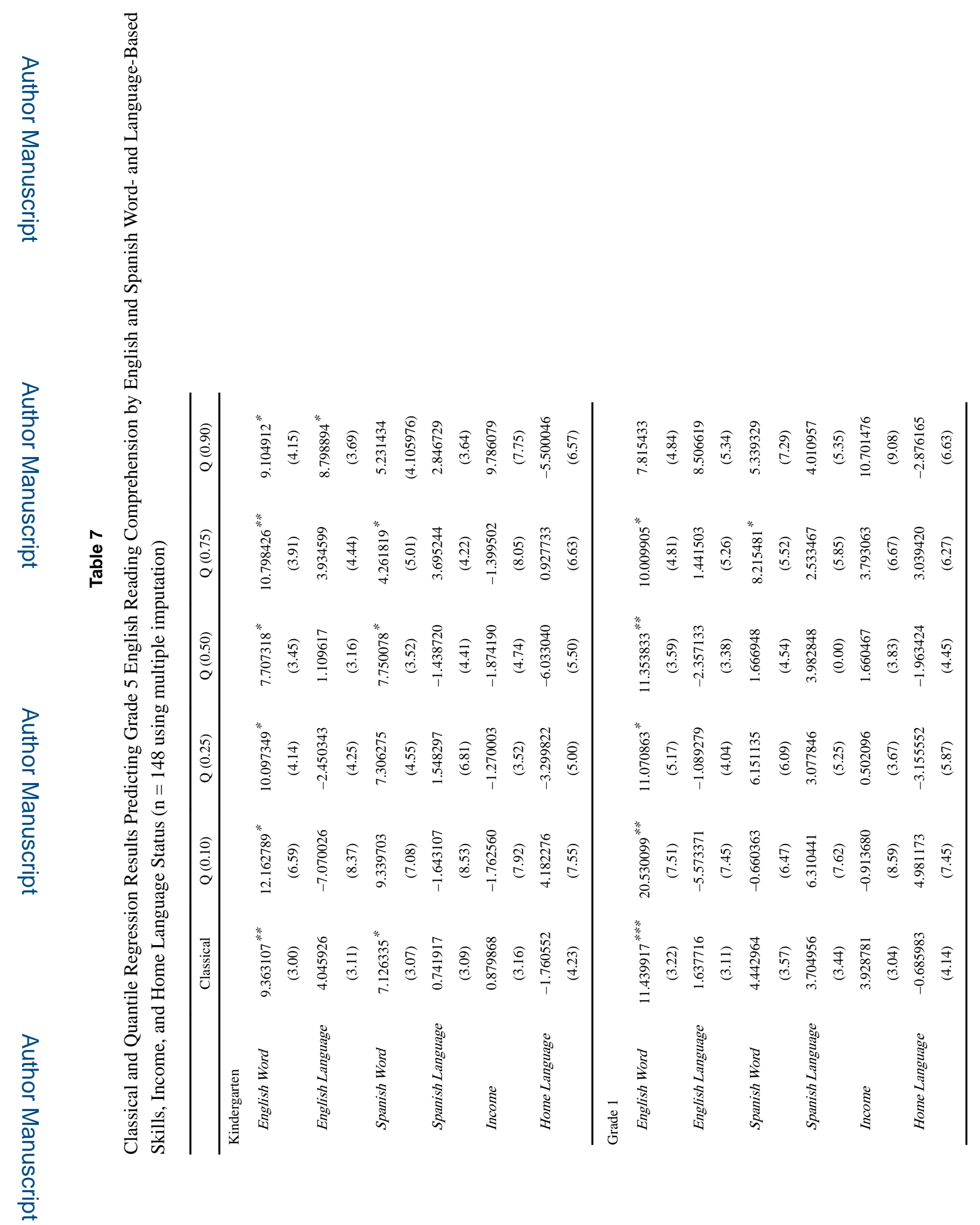

Sci Stud Read. Author manuscript; available in PMC 2019 September 11. 


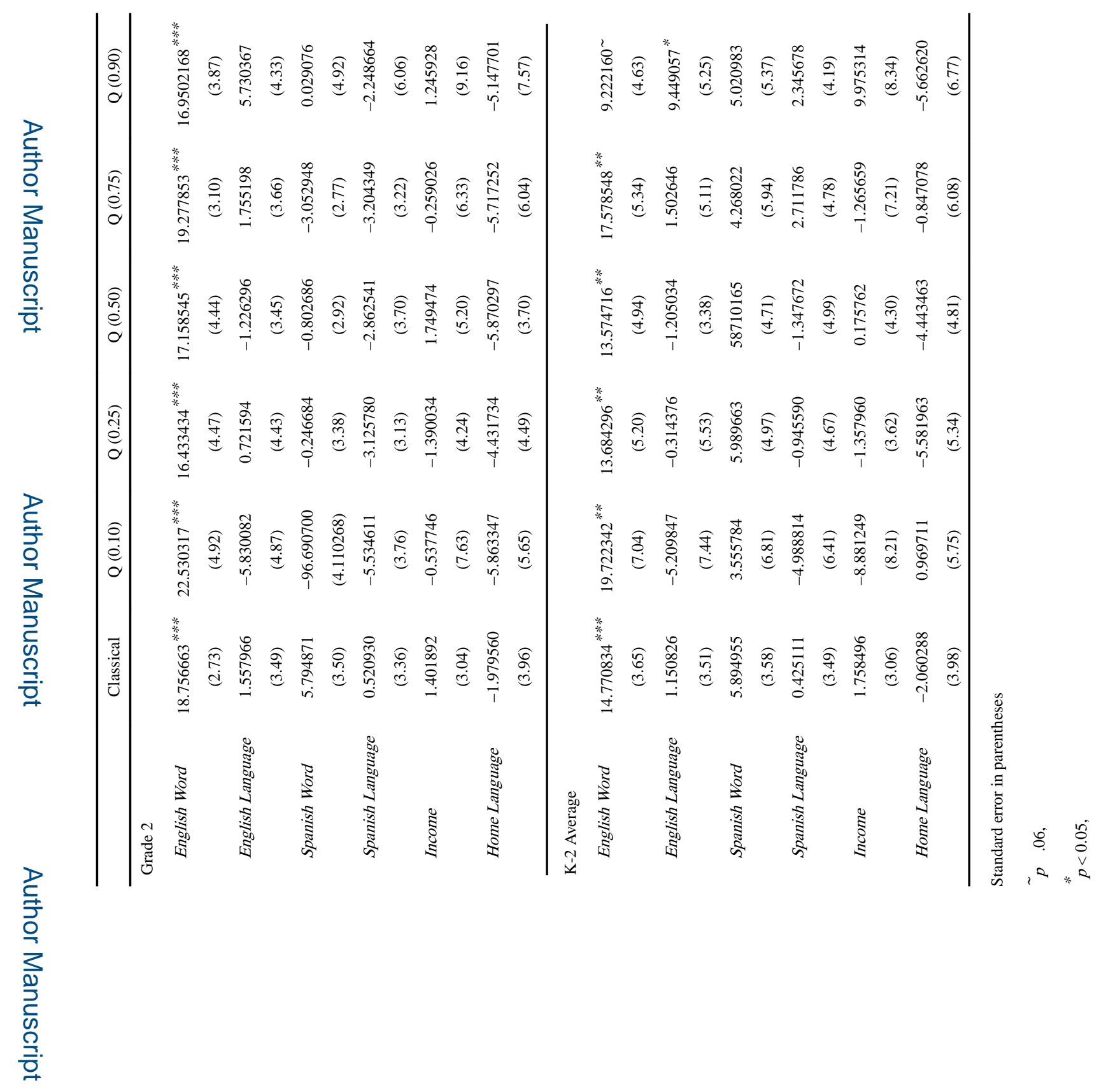

로을

Sci Stud Read. Author manuscript; available in PMC 2019 September 11. 


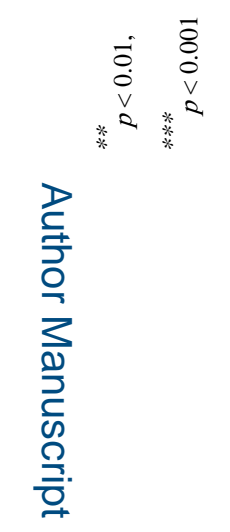

로을

롤

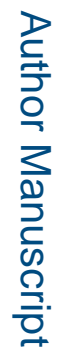

Sci Stud Read. Author manuscript; available in PMC 2019 September 11. 


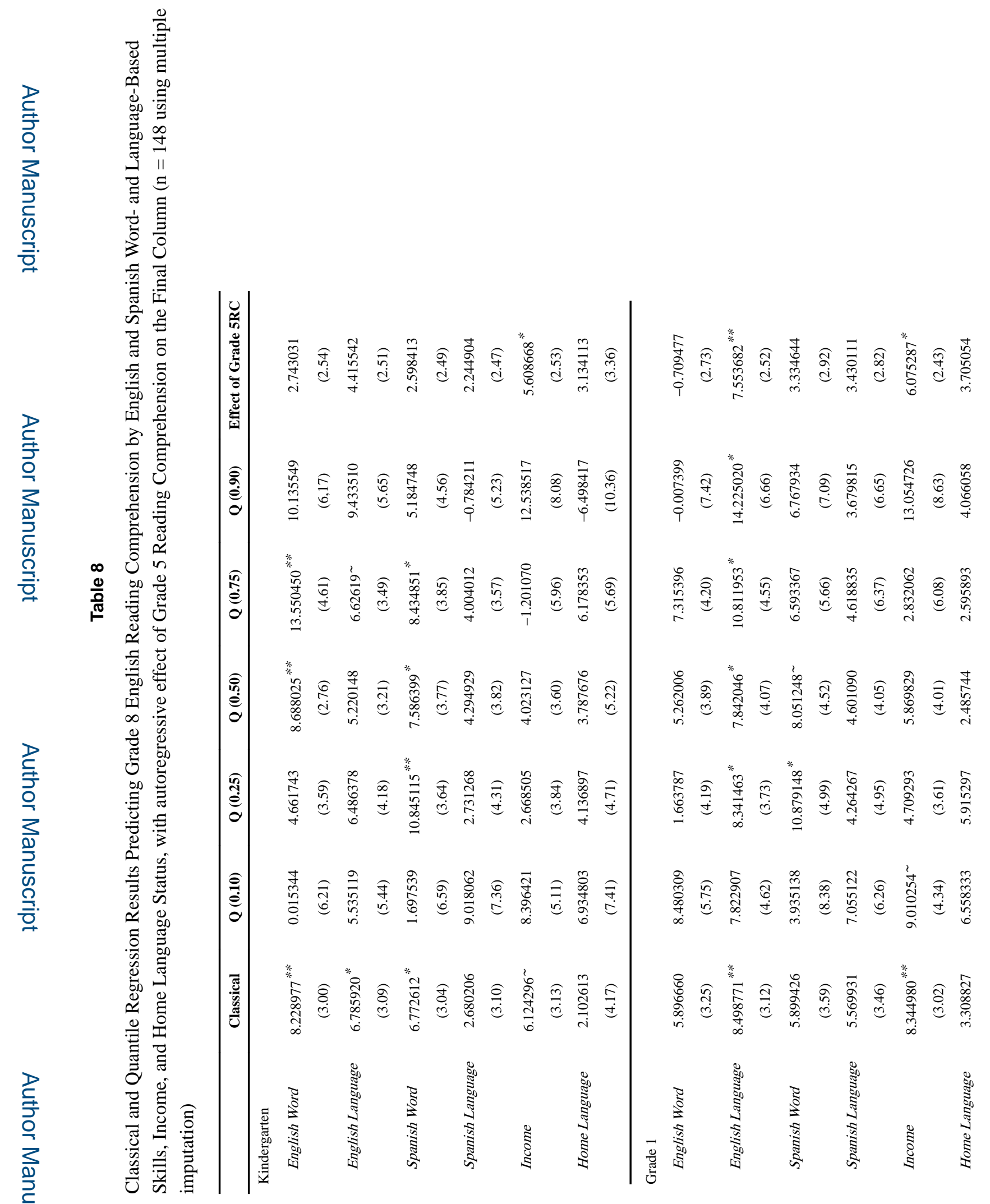


Mancilla-Martinez and Lesaux

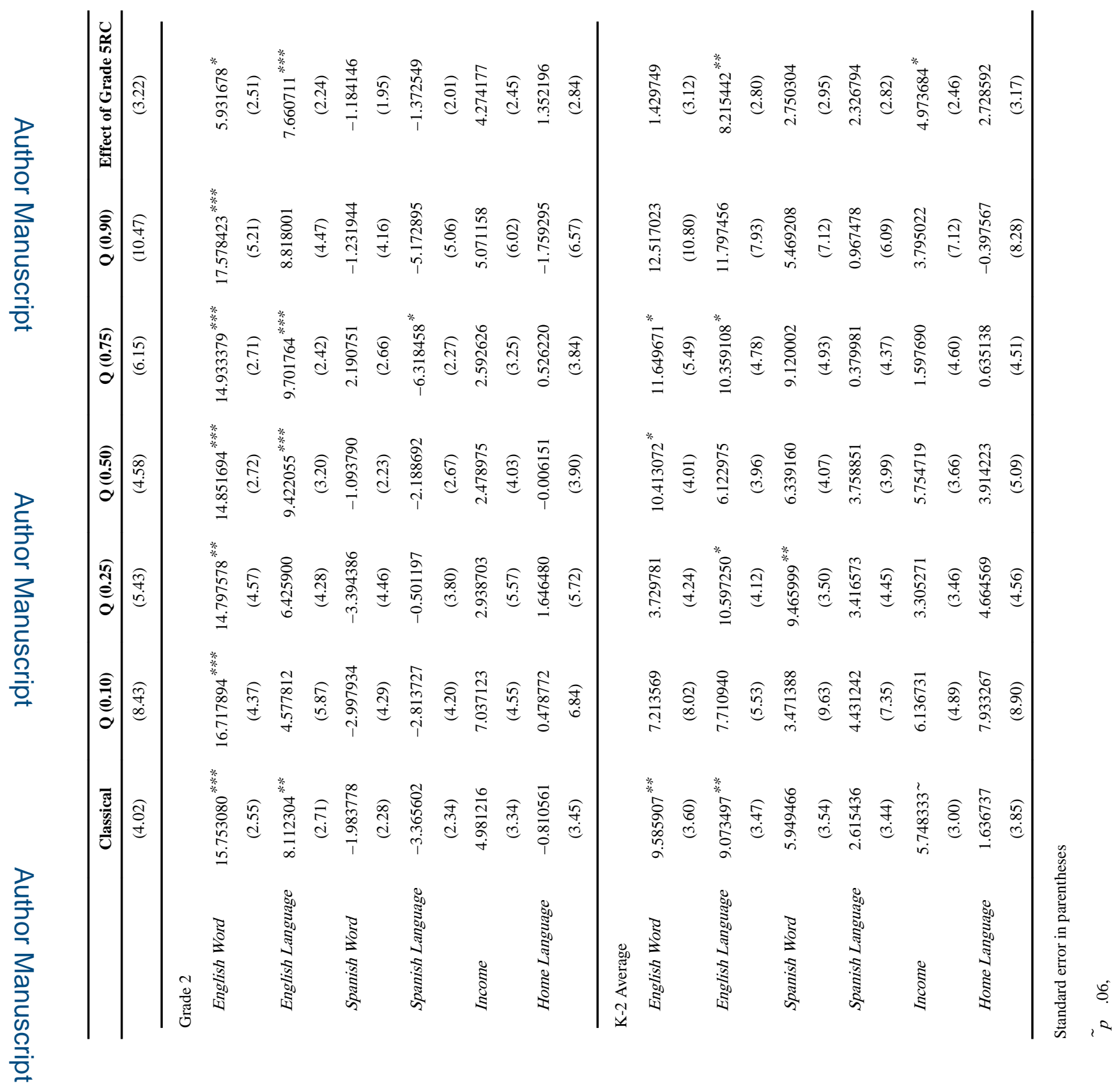

를

Sci Stud Read. Author manuscript; available in PMC 2019 September 11. 


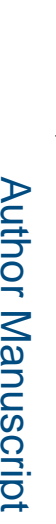

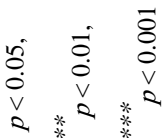

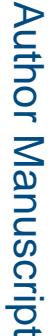

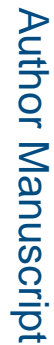

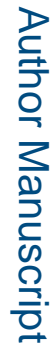

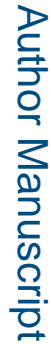

Sci Stud Read. Author manuscript; available in PMC 2019 September 11. 